\title{
Raciocínio condicional: influências pragmáticas
}

\author{
Edilaine Lins Gouveia \\ Antonio Roazzi \\ Karina Moutinho \\ Maria da Graça Bompastor Borges Dias \\ Universidade Federal de Pernambuco
}

David Paul O'Brien

City University of New York

\begin{abstract}
Resumo
Declarações condicionais com a mesma forma sintática mas conteúdos diferentes podem levar a conclusões completamente diferentes. Esse tipo de constatação tem sido apontado por alguns pesquisadores, entre os quais Wason, como evidência da incapacidade da mente humana para compreender as sentenças condicionais. No presente artigo, será discutida a importância de se considerar as influências pragmáticas no raciocínio condicional cotidiano; pois, diferentemente do raciocínio lógico, o raciocínio cotidiano não ocorre no "vazio" e, sim, inserido em um contexto onde as influências pragmáticas se fazem presentes. Inicialmente, serão apresentados alguns preceitos da lógica formal para o raciocínio condicional. Em seguida, a interpretação das sentenças condicionais na linguagem natural. Algumas evidências empíricas para a influência de fatores pragmáticos no raciocínio condicional também serão apresentadas. E, por fim, será discutida a "teoria do se" proposta por Braine e O’Brien que une lógica mental e pragmática no raciocínio cotidiano.
\end{abstract}

Palavras-chave: Raciocínio condicional, Influências pragmáticas, Raciocínio cotidiano, "Teoria do se".

\begin{abstract}
Conditional reasoning: Pragmatical influences.. Conditional declarations with the same syntactic form but different contents may take to completely different conclusions. This point has been highlighted by some researchers (e.g., Wason) as evidence of the inability of the human mind to understand the conditional sentences. In the present article, we discuss the importance of being considered the pragmatic influences in the daily conditional reasoning; because, differently of the logical reasoning, the daily reasoning does not happen in "a vacuum", but inserted in a context where the pragmatic influences occur. Initially, we introduce some precepts of the formal logic for the conditional reasoning. Next, we present the interpretation of the conditional sentences in the natural language. Some empiric evidences for the influence of pragmatic factors in the conditional reasoning will also be discussed. Finally, we consider the "theory of if" proposed by Braine and O'Brien that establishes a connection between the mental and pragmatic logic in the daily reasoning.
\end{abstract}

Key-words: Conditional reasoning, Pragmatic influences, Daily reasoning, "Theory of if".

$\mathrm{A}$ s sentenças condicionais são caracterizadas pela expressão: "se p, (então) q" em que "p" é chamado de cláusula antecedente e "q", de cláusula conseqüente ${ }^{1}$. Independentemente da ordem em que as cláusulas apareçam, a cláusula antecedente se refere à oração com o conectivo e a conseqüente, à oração principal.

O "se" assinala a suposição do falante acerca da possibilidade do evento antecedente ocorrer. Essas sentenças especificam situações hipotéticas, cuja realização, no passado, presente ou futuro, é incerta; ou situações que, por se referirem a conteúdos contrários ao mundo empírico, são contrafactuais, isto é, não podem nem poderiam ocorrer no mundo real.
A função lógica do condicional é estabelecer regras de inferência. A relação "se-então" apresenta uma forma gramatical tal que quando completada com as proposições "p" e "q", por exemplo, tem como resultado a seguinte regra inferencial: "p/q", ou seja, se "p" for estabelecido, "q" pode ser imediatamente concluído (Braine, 1978). O "p" é algum tipo de condição do qual o "q" depende. O relacionamento entre eles é descrito como implicação ou vinculação lógica.

Cada proposição atômica (p, q etc.) terá um valor que pode ser verdadeiro ou falso. $\mathrm{O}$ valor-verdade de proposições compostas ou moleculares, como, por exemplo, o de um condicional " $\mathrm{p}{ }^{\circledR} \mathrm{q}$ ", depende do valor verdade de cada pro- 
Tabela 1.

Tabela de verdade.

\begin{tabular}{ccc|}
\hline Valor verdade das proposições componentes & Valor verdade da proposição condicional \\
\hline P & Q & P $\rightarrow$ Q \\
V & V & V \\
V & F & F \\
F & V & V \\
F & F & V \\
\hline
\end{tabular}

posição atômica e do significado do conectivo lógico, que é fornecido pela tabela de verdade (Tabela 1).

Para o conectivo condicional, a composição condicional composta será verdadeira para quaisquer valores de "p" e "q", exceto para "p" verdadeiro e "q" falso, i.e., não pode haver "p" e "não q".

O raciocínio condicional envolve a realização de inferências com base na relação "se-então" dada. Quatro formas lógicas se seguem dessa relação condicional: Modus Ponens, Modus Tollens, Afirmação do Conseqüente e Negação do Antecedente. Modus Ponens (MP) é o princípio lógico que envolve o raciocínio com as premissas "se p então q. p é verdadeiro" e leva à conclusão "q é necessariamente verdadeiro". No Modus Tollens (MT), as premissas são "se $\mathrm{p}$ então q. q é falso", conduzindo à "p é necessariamente falso". Esses inferências são válidas, pois conduzem a conclusões que são únicas e logicamente necessárias.

A Afirmação do Consequiente (AC) consiste no raciocínio a partir das seguintes premissas: "se p então q. q é verdadeiro" e a Negação do Antecedente (NA) parte das premissas "se p então q. p é falso". De ambas nada se segue, ou seja, não se pode concluir nada que seja logicamente necessário. Essas duas últimas formas são consideradas falácias por não conduzirem a conclusões únicas e logicamente corretas.

Um aspecto importante para o raciocínio dedutivo é a habilidade de raciocinar apenas em termos da relação formal entre as premissas, independentemente do seu valor-verdade empírico. Como a única relação que precisa existir entre as cláusulas de uma sentença condicional é a expressa pela tabela de verdade, proposições totalmente não relacionadas podem aparecer nessas cláusulas, sujeitas apenas à condição de que elas devem ter valores-verdade apropriados para serem consideradas válidas. Observe os exemplos a seguir:

(1) a. Se dois é um número par, então Recife é a capital de Pernambuco.

b. Se dois não é um número par, então Recife é a capital de Pernambuco.

c. Se dois não é um número par, então Recife não é a capital de Pernambuco.

De acordo com a tabela de verdade, eles são totalmente aceitáveis. Em (1a) o antecedente e o conseqüente são verdadeiros. Em (1b) o antecedente é falso, mas o conseqüente, verdadeiro. Em (1c) ambos são falsos. Apesar de não haver qualquer relação lógica, causal ou real entre essas cláusulas, segundo a implicação lógica, essas sentenças são válidas.

No entanto, parece que as pessoas não seguem à risca este tipo de raciocínio. Intuitivamente, sabe-se que afirmações semelhantes às apresentadas no exemplo (1) dificilmente seriam aceitas em meio a uma conversa salvo se inseridas em um contexto que as justificassem, ou seja, em que elas passassem a fazer algum sentido, como no exemplo a seguir:

A: Dois não é um número par!

B: Claro que dois é um número par.

A: Não é

B: Se dois não é um número par, então Recife não é a capital de Pernambuco.

Desta forma, parece que, em situações naturais de interação, as pessoas não seguem à risca os preceitos da lógica formal. Devido ao papel central que desempenha no raciocínio científico e à sua onipresença no raciocínio cotidiano, os estudos sobre os condicionais e as teorizações sobre como as pessoas raciocinam com eles floresceram bastante nos últimos anos.

A habilidade de resolver problemas envolvendo relações condicionais é fundamental para o desenvolvimento do raciocínio dedutivo (Girotto, Light \& Colbourn, 1988) e, por conseguinte, desempenha papel central no raciocínio científico. Como destacam O'Brien e Overton (1980), a relação entre um conjunto de princípios científicos e uma hipótese bem como a relação entre a hipótese e a conclusão são relações condicionais.

Paralelamente, o raciocínio condicional também é fundamental na vida diária. A todo momento, ao tomar decisões, as pessoas estão levando em consideração diferentes possibilidades, raciocinando a partir delas e decidindo pelo que lhes parece melhor ou mais adequado. A habilidade para ter pensamentos condicionais é parte básica do equipamento mental humano. Ela amplia a visão de mundo, que ficaria bastante limitada em sua ausência. De que adiantaria, por exemplo, reconhecer que um carro em alta velocidade vem em sua direção, se não fosse possível perceber que se você não sair imediatamente do local em que está será atropelado?

Os estudiosos do raciocínio humano têm tentado compreender como as pessoas raciocinam com e a partir das sentenças condicionais em seu cotidiano. Ou seja, como essas sentenças são interpretadas na linguagem natural, tema abordado a seguir. 


\section{Interpretação das sentenças condicionais na linguagem natural}

\section{Multiplicidade de interpretações}

Termos como 'condicional', 'causal' e 'concessivo' são parte de um inventário terminológico fornecido pela gramática tradicional para a caracterização das cláusulas adverbiais. Essas distinções, embora aparentemente claras, se referem a um contínuum de difícil separação (König, 1986, p.230). Apesar da expressão "se $p$ então $q$ " ser geralmente escolhida para expressar a relação condicional, ela também pode ser interpretada de formas diferentes. Em alguns casos, a distinção entre condicional e causal é difícil de ser realizada, como exemplifica este autor:

(2) A: Ken diz que morou no Japão por sete anos.

B: Se ele morou tanto tempo no Japão, deve falar japonês muito bem.

Percebe-se, neste exemplo, que o condicional tem significado equivalente ao do conectivo causal. Em alguns contextos, a sentença condicional pode receber interpretação similar à da sentença concessiva, expressando negação de expectativa, como ele apresenta a seguir:

(3) Mesmo se Peter vier, eu não estarei aqui.

Paralelamente, existem outras construções com funções diversas que, em certas circunstâncias, servem para marcar relação hipotética entre antecedente e conseqüente, ou seja, agem como condicionais. Comrie (1986, p. 83) fornece dois exemplos para a língua inglesa:

(4) a. Although he may look a fool, he's actually very intelligent.

b. Whenever he came late, he was scolded.

Ele afirma que modificações apropriadas na modalidade das cláusulas concessivas podem produzir resultados que recebam a mesma interpretação das cláusulas condicionais com o even, como no exemplo (4a) que pode ser equiparado a "Even if he looks fool, he's actually very intelligent". E ressalta que a inserção do indefinido ever nas cláusulas temporais pode levar à interpretação idêntica àquela dos condicionais. $\mathrm{O}$ exemplo (4b) pode ser claramente interpretado como "If he came late, he was scolded".

A idéia de condicionalidade também pode estar presente em sentenças coordenadas.

(5) Aprenda a dirigir e será contratado como motorista.

Percebe-se que a condição para ser contratado como motorista é aprender a dirigir e poderia ter sido expressa como "Se você aprender a dirigir, será contratado como motorista".

Em suma, a presença do conectivo condicional não é suficiente para garantir que a sentença seja interpretada como condicional. Paralelamente, observa-se que outros tipos de conectivos podem, sob certas circunstâncias, receber a interpretação de condicionalidade. Mesmo na ausência de qualquer conectivo, como demonstra o exemplo (5), esta interpre- tação pode ocorrer. Ou, nas palavras de König (1986), a simples presença de um conectivo, não é suficiente para determinar a que categoria a cláusula adverbial marcada pertence. Desta forma, faz-se necessário estabelecer as distinções entre o significado da sentença condicional e a interpretação de condicionalidade.

\section{Significado $x$ interpretação: distinções necessárias}

Comrie (1986), reconhecendo a influência dos fatores pragmáticos na interpretação da sentença condicional, considera importante fazer a distinção entre o significado da construção e sua interpretação. Atendo-se ao significado, ele aproxima a lógica formal do raciocínio cotidiano ao assumir que a implicação material faz parte da caracterização do condicional na linguagem natural. Observe a sentença abaixo apresentada por ele (Comrie, 1986, p.78).

(6) Se hoje é Domingo, então o padre está na igreja.

Essa sentença, enunciada por alguém que não tem certeza de que dia da semana está, dá margem às seguintes possibilidades: que hoje seja domingo e que o padre esteja na igreja; que não seja domingo, e, neste caso, a proposição continua sendo verdadeira caso o padre esteja ou não na igreja. O que está excluída é a possibilidade de ser domingo e o padre não estar na igreja. Como esta, muitas sentenças condicionais na linguagem natural, de fato, recebem uma interpretação congruente com essas possibilidades permitidas pela lógica formal.

Desta forma, Comrie (1986) assume que a implicação material da lógica formal é parte da caracterização do condicional na linguagem natural. No entanto, admite que, examinando enunciações espontâneas em contextos reais, a construção condicional também pode receber outras interpretações, como citado anteriormente. E destaca que muitos aspectos da interpretação que são tradicionalmente atribuídos à semântica da construção condicional são, de fato, influências pragmáticas, e não partes do significado da sentença. Essa influências podem ser cancelados em circunstâncias apropriadas. Como se pode perceber no seguinte exemplo:

(7) Se você mexer no ventilador, eu vou bater em você.

Sob condições normais, seria interpretado como indicando que se o interlocutor realizar a ação referida, o falante irá bater nele, i.e., o se é interpretado como se e somente se. Porém, se não é necessariamente interpretado desta forma:

(8) Se ele apostar neste cavalo, vai perder dinheiro. Se bem que, de uma forma ou de outra, ele vai acabar perdendo esse dinheiro.

No contexto em que o exemplo (7) é normalmente pronunciado, a implicação conversacional de que o se deve ser interpretado como bicondicional é natural: a enunciação pretende ser uma proibição. Se o falante bater no interlocutor de qualquer forma ou se o ouvinte assume que apanhará de qualquer forma, então a motivação de proibição é perdida, 
i.e., a enunciação se torna incoerente. Entretanto, no exemplo (8), essa interpretação não é viável.

Haiman (citada em Hirata, 1999), concordando com Comrie, afirma que a implicação material não basta, pois não reflete o que ocorre nos condicionais comuns na língua. Diferentemente do que propõe a tabela de verdade, na linguagem natural os condicionais requerem forte ligação entre a cláusula antecedente e a conseqüente. Segundo Comrie (1986), em muitos casos, essa ligação é causal, i.e., o conteúdo da cláusula antecedente deve ser interpretado como causa do conteúdo da cláusula conseqüente como no exemplo 7.

Entretanto, Comrie, (1986, p.81) afirma que, na linguagem, as relações causais envolvem não apenas o conteúdo literal das proposições, mas também a motivação do falante para fazer determinada enunciação, ilustrando com o exemplo a seguir:

(9) João é um ladrão, porque eu o vi roubando

A interpretação mais comum para este exemplo não é que o fato de eu ter visto João roubando o tenha transformado em um ladrão, mas que vê-lo roubando é a razão para eu acreditar que ele é um ladrão.

Com relação aos condicionais, Comrie (1986, p.81) fornece os seguintes exemplos:

(10) Se Bismarck é a capital da Dakota do Norte, então Pierre é a capital da Dakota do Sul.

Nas circunstâncias normais, essa sentença seria rejeitada como incoerente, pois não há nenhuma relação causal entre as proposições. Porém, inserida no seguinte diálogo, ela se torna coerente:

A: Qual é a capital da Dakota do Sul?

B: Eu não tenho certeza. Bismarck e Pierre são as capitais das duas Dakotas, mas não tenho certeza de qual é qual.

A: Bismarck é a capital da Dakota do Norte.

B: Se Bismarck é a capital da Dakota do Norte, então Pierre é a capital da Dakota do Sul.

Aqui, o vínculo causal não está diretamente entre Bismarck ser a capital da Dakota do Norte e Pierre, da Dakota do Sul, mas entre o conhecimento de A de que Bismarck é a capital da Dakota do Norte e a base epistêmica da afirmação de B de que Pierre é a capital da Dakota do Sul.

Em resumo, Comrie (1986) argumenta que a construção condicional terá, pelo menos, uma interpretação onde a relação lógica entre as proposições é a mesma para a implicação material da lógica formal, não excluindo a possibilidade de interpretações adicionais, como a bicondicional. Enfatiza que, diferentemente da lógica formal onde a construção condicional não vincula nenhuma das proposições, na linguagem natural é imprescindível que haja uma relação entre elas. O caráter dessa relação, segundo esse autor, é causal (quer seja do antecedente para o conseqüente ou da motivação para fazer a enunciação).

Percebe-se que há aproximações entre a interpretação das sentenças condicionais na linguagem natural e o raciocínio condicional de acordo com a lógica formal. Várias teorias sobre como as pessoas raciocinam com e a partir de sentenças condicionais vêm sendo elaboradas sem que haja consenso entre elas com relação aos processos subjacentes ao raciocínio condicional ${ }^{2}$. Entretanto, uma estratégia comum a estas teorias é comparar a resolução de problemas condicionais por pessoas que não receberam qualquer instrução em lógica formal com o raciocínio condicional "correto", i.e., que segue os preceitos da lógica formal. A seguir, serão apresentadas algumas evidências empíricas a este respeito.

\section{Raciocínio Cotidiano: evidências empíricas}

Alguns estudos (e.g., Rumain, Connell \& Braine, 1983; Taplin, 1971) sugerem que as pessoas dificilmente erram ao tentar resolver problemas na forma Modus Ponens. Os do tipo Modus Tollens também são de fácil resolução, embora o desempenho das pessoas pareça cair um pouco quando comparados ao MP.

O mesmo não ocorre diante dos silogismos inválidos. Nestes, em vez de afirmar que nada se segue, ou seja, que não é possível chegar a nenhuma conclusão logicamente necessária, as pessoas geralmente produzem falácias, tais como exemplificado na Tabela 2.

Tabela 2 .

Exemplos dos tipos de silogismos.

\section{Modus Ponens}

Se a professora chegou em tempo, ela deu aula.

A professora chegou em tempo.

Logo, ela deu aula.

Afirmação do conseqüente

Se a professora chegou em tempo, ela deu aula.

A professora deu aula.

Logo, ela chegou em tempo.

\section{Modus Tollens}

Se a professora chegou em tempo, ela deu aula.

A professora não deu aula.

Logo, ela não chegou em tempo.
Se a professora chegou em tempo, ela deu aula.

A professora não chegou em tempo.

Logo, ela não deu aula. 
Ao comparar o desempenho das pessoas resolvendo tarefas que exigem o raciocínio condicional com o que seria esperado pela tabela de verdade, tem-se verificado que ora elas seguem o proposto por esta tabela, ora falham em fornecer as respostas esperadas. Esse resultado tem sido apontado por alguns pesquisadores (e.g., Wason, 1966; Wason \& Johnson-Laird, 1972) como evidências de que as pessoas têm apenas uma compreensão superficial da sentença condicional. Em outras palavras, segundo eles, a mente humana não dispõe de competência lógica para o raciocínio condicional.

O’Brien, Dias, Roazzi e Braine (1998), discordando desta interpretação, afirmam que esses resultados apenas evidenciam que a mente humana não segue o proposto pela tabela de verdade. Eles declaram que :

\footnotetext{
... tais respostas mostram que a tabela de verdade não captura o que as pessoas compreendem sobre os condicionais. De fato, ver os condicionais através das lentes da tabela de verdade obscurece o papel dos condicionais no raciocínio cotidiano: se indica suposição e, ao raciocinar, as pessoas geralmente supõem algo para descobrir como seria diante dessa suposição ${ }^{3}$...(p.246)
}

Assim, argumentam que a natureza suposicional do raciocínio condicional não é contemplada pela tabela de verdade; não correspondendo, portanto, a como as pessoas raciocinam cotidianamente com esse conectivo. Em contrapartida, sugerem que os processos de raciocínio podem ser descritos como aplicações de esquemas de inferência e propõem uma distinção entre processos de raciocínio pragmáticos e analíticos (ou formais). O raciocínio pragmático envolve o uso do conhecimento do mundo real para interpretar e processar as premissas usadas como base para o raciocínio. $\mathrm{O}$ raciocínio analítico, por sua vez, supõe uma habilidade para raciocinar com premissas independentemente de sua base empírica.

Pesquisas demonstram que as pessoas raciocinam corretamente diante das inferências válidas, mas cometem erros lógicos com as inválidas. Estes erros advêm da interpretação errônea do condicional como bicondicional - se e somente se. Assim, diante de "se p então q", as pessoas concluem que "se não $p$ então não q". De acordo com esta interpretação, o antecedente é tanto suficiente quanto necessário para o conseqüente, o que torna todas as quatro inferências são válidas.

Entretanto, apesar de usualmente cometerem esse tipo de erros, existem situações em que as pessoas conseguem raciocinar corretamente com os silogismos inválidos. Rumain, Connell e Braine (1983), por exemplo, demonstraram que oferecendo exemplos de outras condições que também podem levar ao conseqüente, é possível suprimir a interpretação bicondicional. Eles apresentaram a crianças e adultos silogismos com a premissa condicional nas seguintes formas:

a. Se p então q (usual)

b. Se $\mathrm{p}$ então $\mathrm{q}$, mas Se não $\mathrm{p}$ então $\mathrm{q}$ pode ser verdadeiro ou falso. E, se q, então p pode ser verdadeiro ou falso (expandida)

c. Se $\mathrm{p}$ então q mas Se não $\mathrm{p}$ então $\mathrm{q}$ pode ser verdadeiro ou falso (parcialmente expandida)
A premissa condicional na forma expandida apresenta outras condições que também podem levar ao conseqüente, contra-ordenando explicitamente que a premissa condicional seja interpretada como bicondicional. Com a premissa parcialmente expandida, esta contra-ordem é implícita. E, na premissa em sua forma usual, não há qualquer contra-ordem à interpretação de bicondicionalidade. Os pesquisadores constataram que, nos problemas que apresentavam a premissa condicional nas formas não usuais, as falácias não foram cometidas.

Este estudo demonstra que, em certas circunstâncias, adultos e crianças conseguem raciocinar corretamente a partir de premissas condicionais, sem que cometam falácias frente aos silogismos inválidos.

Tem-se verificado também que, apesar das pessoas comumente realizarem as inferências válidas, em algumas situações elas resistem em fazê-las. Byrne (citada em Vadeboncoeur \& Markovits, 1999) foi a primeira a reportar a supressão de inferências logicamente válidas. Ela apresentou argumentos condicionais tais como:

(11) a. Se Maria encontra seu amigo, então ela vai para o jogo.

Maria encontra seu amigo.

b. Se Maria tiver dinheiro suficiente, então ela vai para o jogo.

Diante de (11a), a maioria dos participantes produziu a conclusão válida "Maria vai para o jogo". Mas, quando o argumento (11a) foi apresentado juntamente com a premissa adicional (11b), o número de inferências válidas caiu consideravelmente. Confrontados com as premissas (11a) e (11b), as pessoas parecem se valer de seu conhecimento de mundo para concluir que apenas encontrar o amigo não é suficiente para que Maria possa ir ao jogo, pois a premissa (11b) levanta dúvidas com relação a ela ter dinheiro suficiente para, por exemplo, se deslocar de onde está até o local do jogo, pagar a entrada no jogo e se deslocar de volta após o final da partida. Desta forma, ao levar em consideração premissas não colocadas na situação-problema, as pessoas não realizam as inferências válidas.

Um exemplo prático da não realização de uma inferência válida é o desastre de Chernobyl, citado por Byrne, Espino e Santamaria (1999, p.347), a seguir:

"Imagine que você está trabalhando em uma usina nuclear durante uma emergência e seu trabalho é descobrir o que está errado. Suponha que você conheça a seguinte regra geral: Se é para prosseguir com o teste, a turbina tem que estar funcionando rápido o bastante para gerar força de emergência. E suponha que o sistema de monitoração informa que a turbina não está funcionando rápido o bastante. $\mathrm{O}$ que você deveria inferir? Uma inferência MT válida seria que o teste não deve prosseguir... Os trabalhadores de Chernobyl não inferiram, em tempo, que deveriam parar o teste e, como resultado desta dificuldade inferencial, o desastre nuclear de Chernobyl ocorreu". ${ }^{4}$ 
Para esses autores, os trabalhadores de Chernobyl podem não ter realizado a inferência por terem considerado suposições adicionais, tais como se os procedimentos de segurança devem ser rigorosamente seguidos em tal situação. Evidencia-se, assim, que mesmo as inferências válidas que usualmente são realizadas sem dificuldades podem, sob certas circunstâncias, ser suprimidas. A questão que se coloca é: que variáveis estão influenciando no desempenho das pessoas de forma a ora viabilizar o raciocínio lógico correto e ora impedi-lo?

A este respeito, Vadeboncouer e Markovits (1999), voltando-se especificamente para a influência da instrução sobre o desempenho em tarefas de raciocínio condicional, identificaram que o tipo de instrução fornecida influencia nas respostas obtidas. Quando se diz aos participantes para considerar as premissas como eles as considerariam em sua vida cotidiana, tendem a concluir com incerteza frente aos silogismos tipo Modus Ponens e Modus Tollens. Porém, se a natureza lógica da tarefa e a necessidade de considerar as premissas como verdadeiras são enfatizadas, os participantes conseguem tirar conclusões válidas, mesmo se as premissas vão contra suas crenças.

As instruções parecem funcionar como um indicador do tipo de raciocínio requerido para resolver a tarefa. As instruções "lógicas", ao explicitar para as pessoas que devem abandonar sua forma de raciocínio usual, i.e., desconsiderar seu conhecimento contextual ou empírico para reinterpretar as premissas, induzem-nas a um tipo de raciocínio analítico ou formal. Raciocínio este que reflete a habilidade para usar proposições hipotéticas como verdadeiras e produzir conclusões logicamente válidas a partir delas. Em outras palavras, a ênfase na necessidade de assumir a veracidade das premissas poderia ajudar os participantes a mudar de uma forma de raciocínio pragmático (cotidiano) para a forma de raciocínio lógico.

Algumas pesquisas também têm constatado que crianças conseguem, em determinadas situações, apresentar raciocínio correto e justificativas teóricas para suas respostas. Dias e Harris (1988), por exemplo, destacam a importância do contexto no qual o silogismo é apresentado para a forma de resolução do mesmo por crianças de 4 e 5 anos de idade. Elas não só foram capazes de resolver silogismos com conteúdo contrário ao seu conhecimento empírico como forneceram justificativas teóricas para sua resposta quando os mesmos eram apresentados em situação de faz-de-conta. No entanto, diante do mesmo silogismo apresentado em situação "normal", i.e., sem envolver contexto de fantasia, as crianças falhavam na sua resolução e tendiam a dar justificativas empíricas para as suas respostas.

A partir desses resultados, parece plausível pensar que as crianças interpretaram a tarefa com o silogismo apresentado em situação "normal" como um teste de conhecimentos similar aos que ocorrem nas escolas. Desta forma, não faria qualquer sentido chegar a uma conclusão cujo conteúdo é sabidamente contrário ao do mundo empírico. Ao passo que, a situação de fantasia abre a possibilidade de se considerar a existência de mundos alternativos em que as coisas não têm que ser exatamente iguais às do mundo físico. Neste contexto, as conclusões contrárias ao seu conhecimento de mundo são aceitáveis. De forma similar às instruções fornecidas para os adultos no experimento de Vadeboncouer e Markovits, o contexto no qual as tarefas são apresentadas parece sinalizar melhor para as crianças o tipo de raciocínio requerido pela atividade.

Em conjunto, esses estudos indicam que adultos e crianças têm capacidade de resolver silogismos lógicos de forma apropriada. Parece, entretanto, que seus erros decorrem da interpretação da tarefa de forma diferente daquela esperada pelo pesquisador. Ou seja, são devidos aos processos pragmáticos de compreensão. É importante considerar então que o raciocínio não ocorre no "vazio", e sim inserido em um contexto, onde as influências pragmáticas se fazem presentes.

Assim, para compreender como as pessoas raciocinam cotidianamente com e a partir de sentenças condicionais é necessário se dispor de uma teoria que considere não só os aspectos lógicos do raciocínio, mas também a influência do contexto no qual as sentenças estão sendo produzidas e interpretadas, o conhecimento de mundo das pessoas. Na sessão seguinte, será apresentada uma teoria proposta por Braine e O'Brien (1998a) que parece bastante apropriada para este propósito.

\section{Teoria do se: unindo lógica mental e pragmática}

A Teoria do se possui três partes: o verbete léxico, o programa de raciocínio e os processos pragmáticos de compreensão.

O verbete léxico corresponde ao conhecimento sobre o se que está armazenado na memória semântica e independe de qualquer informação contextual. Para compreender melhor, observe os problemas a seguir:

$$
\begin{aligned}
& \text { a. Das premissas "p se q" e "não p", conclui-se "não q"; } \\
& \text { b. Das premissas "p ou q" e "não p", conclui-se "q"; } \\
& \text { c. Das premissas "p e q" e "não p", pode-se concluir apenas que } \\
& \text { possivelmente alguma informação está errada. }
\end{aligned}
$$

Esses problemas diferem apenas com relação à partícula usada no meio da primeira premissa, pois o contexto, o conteúdo e a forma são os mesmos. As diferenças de interpretação dizem respeito às informações sobre essas partículas que estão disponíveis na memória semântica, isto é, ao verbete léxico dessas partículas (Braine \& O'Brien, 1998a).

Uma forma de se conceber o se que poderiam servir de hipótese para o verbete léxico é a fornecida pela abordagem semântica da lógica formal. Entretanto, conforme apresentado anteriormente, há uma concordância geral de que o raciocínio cotidiano não segue a tabela de verdade ${ }^{5}$.

A hipótese para o verbete léxico adotada por esta teoria se vincula à da abordagem sintática da lógica formal, que não faz referência aos valores-verdade das proposições. Ela se preocupa com a forma lógica do argumento, independentemente de seu conteúdo. $\mathrm{O}$ foco recai sobre os esquemas de inferência. Cada esquema define um tipo particular de inferência, especificando que conclusão pode ser tirada a 
partir de informações apresentadas sob formas específicas (O’Brien, 1987).

Braine e O'Brien (1998a) defendem que, para o conectivo condicional, os dois esquemas que descrevem as formas nas quais a sentença condicional podem ser usadas no discurso são o MP e o Esquema para Prova Condicional (EPC).

$\mathrm{O}$ esquema de dedução natural que permite usar a declaração condicional na linha de raciocínio é o $\mathrm{MP}$, segundo o qual, quando se sabe que a proposição condicional e seu antecedente são verdadeiros, pode-se imediatamente afirmar a verdade do conseqüente.

O EPC permite introduzir a declaração condicional na linha de raciocínio, declarando que, quando se pode derivar o conseqüente de um condicional a partir de um conjunto de premissas tomadas juntamente com a suposição hipotética do antecedente deste condicional; pode-se, então, afirmar o condicional com base apenas nas premissas. Em outras palavras, para derivar ou avaliar "Se p então...", primeiro suponha "p"; para qualquer proposição, "q", que segue da proposição de "p" tomada junto com outra informação assumida, pode-se afirmar "Se p então q".

Para O’Brien, Dias, Roazzi e Braine (1998), apesar do significado básico da partícula se ser fornecido por esses esquemas de inferências; ele é revelado principalmente pelo esquema para prova condicional. Pois argumentam que afirmar uma declaração com o se é afirmar uma suposição e, afirmar uma declaração com o então é afirmar o que se segue a partir dessa suposição. Compreendendo o se desta forma, fica claro porque as inferências MP são válidas. A afirmação de "se p então q" indica que "q" é derivável da suposição de "p". Então, "q" se segue quando a afirmação de "p" remove a base condicional da prova. Deste modo, a inferência MP é correta porque herda a derivação do conseqüente que era feita sob o EPC.

O programa de raciocínio se refere a um programa de dedução natural que modela como o sujeito constrói uma série de raciocínio usando os esquemas. Ele descreve como cada esquema que será aplicado em determinado ponto da série de raciocínio é selecionado. As estratégias de raciocínio incluem rotinas de raciocínio direto, que são universais, e estratégias de raciocínio mais sofisticadas ${ }^{6}$.

No entanto, Braine e O'Brien (1998a) afirmam que a construção da partícula lógica em determinado contexto tem origem no verbete léxico conjuntamente com os processos de compreensão, pois a forma como a palavra é construída no contexto depende de muitos outros fatores além do verbete léxico, como, por exemplo, do conhecimento anterior sobre o assunto que está sendo falado, dos processos de compreensão, da maior plausibilidade de algumas construções quando comparadas a outras etc. Assim, dependendo do contexto em que são usadas, os significados das partículas podem ser alterados. A terceira parte da teoria se refere aos princípios pragmáticos. Estes se aplicam à compreensão como um todo, uma vez que o programa de raciocínio aplica os esquemas de inferência às informações compreendidas pelas pessoas.

Esses autores apresentam três princípios gerais para influência dos fatores pragmáticos na compreensão. $\mathrm{O}$ primeiro se refere à influência do conteúdo na forma como as proposições são construídas. Tem sido amplamente reconhecido na literatura (e.g., Byrne, Espino \& Santamaria, 1999; Dias, 1996; Markovits, 1988; Vadeboncoeur \& Markovits, 1999) que as pessoas se baseiam em seu conhecimento prévio para dar sentido à situação atual. Assim, interpretações que lhes parecem plausíveis, coerentes com sua visão de mundo, são mais provavelmente construídas do que outras que parecem pouco plausíveis. Desta forma, as pessoas podem, diante de tarefas lógicas, estar se baseando em premissas diferentes daquelas propostas pelo experimentador, se elas lhes parecerem pouco plausíveis.

O segundo princípio se refere à lógica da conversação formulada por Grice (citado em Guimarães, 1995). De acordo com este autor, há uma diferenciação entre o significado literal de um enunciado e o sentido intencional do falante ao enunciá-lo. Ele argumenta que o sentido do que o interlocutor diz deve ser interpretado levando em conta tanto o sentido literal do que foi dito, ou seja, o que o enunciado significa independentemente de sua situação de uso; quanto a situação em que é dito.

Guimarães (1995) afirma que, segundo Grice, a conversação é regida pelo Princípio da Cooperação que informa ao falante para fazer sua contribuição conversacional tal como é requerida, no momento em que ocorre, pelo propósito ou pela direção do intercâmbio conversacional em que ele está engajado. No interior desse princípio, funciona um conjunto de regras denominadas de Máximas Conversacionais, que são as seguintes: faça com que sua contribuição seja tão informativa quanto requerida para o propósito corrente da conversação, i.e. faça com que ela não seja nem menos nem mais informativa do que requerida; não diga o que acredita ser falso; seja relevante e claro.

Assim, tendo em vista que a conversação é regida pelo Princípio de Cooperação e pelas Máximas, o ouvinte procura dar um sentido ao enunciado que esteja de acordo com essas implicações conversacionais. Para isso, as pessoas acreditam que seus interlocutores estão sendo o mais informativo, verdadeiro, relevante e claro que conseguem. Esta crença interfere na compreensão, pois permite que muitas inferências desnecessárias sejam feitas. É possível que o falante não tenha certeza se os componentes da proposição são verdadeiros ou não. Essa incerteza é desconsiderada pelo ouvinte. Diante das tarefas lógicas, as pessoas podem assumir as informações disponibilizadas no problema como verdadeiras e relevantes para a resolução da tarefa, sem se preocupar em verificá-las e, por conseguinte, partindo de premissas incorretas chegar a conclusões erradas.

Embora o significado das partículas lógicas seja fornecido pelos seus esquemas de inferência básicos, ele pode ser ampliado pelas inferências convidadas, que é o terceiro princípio. Especificamente com relação às sentenças condicionais, Geis e Zwicky (1971) constataram que a sentença na forma "se p então q" convida à inferência "Se não p então não q". Observe os exemplos a seguir:

(12) a. Se você continuar gritando, vai ficar rouco. 
b. Se Maria ajudar a preparar o lanche, vai poder participar do piquenique.

c. Se Alexandre estivesse aqui, Amélia estaria rindo à toa.

Esses exemplos transmitem a idéia de que o evento descrito na cláusula conseqüente só ocorrerá (ou ocorreria) se o evento da cláusula antecedente ocorrer (ou ocorresse). Esse princípio interpretativo faz a conexão entre a forma lingüística da sentença condicional e a tendência de funcionamento da mente humana de transformar o condicional em bicondicional, citada anteriormente. As pessoas fazem pragmaticamente estas inferências convidadas a menos que tenham motivo para acreditar que não são apropriadas (e.g., Rumain, Connell \& Braine, 1983).

Em suma, de acordo com esta teoria o significado básico do se é fornecido pelos esquemas de inferência MP e EPC, sendo particularmente revelado por este último em conjunto com as estratégias de raciocínio. No entanto, o uso dessas regras de inferência é limitado por princípios pragmáticos que são usados para interpretar o significado do termo lógico no contexto dado. Como as regras de inferência são aplicadas ao produto do processo de compreensão, a ativação de princípios pragmáticos pode levar a interpretações diferentes das premissas; gerando, portanto, conclusões diferentes daquelas oriundas do raciocínio exclusivamente a partir das premissas.

Em outras palavras, como o raciocínio cotidiano se utiliza de todas as informações disponíveis, fatores extra-lógicos podem fornecer premissas adicionais ao raciocínio. Desta forma, muitos erros decorrem dos princípios pragmáticos que afetam a compreensão.

A teoria do se propõe, assim, que a mente humana dispõe de um procedimento semântico para o se que, diferentemente do proposto pela tabela de verdade, baseia-se em regras de inferência. Considera, entretanto, que o raciocínio condicional não depende exclusivamente das inferências lógicas, pois o significado da partícula lógica pode ser ampliado por variáveis pragmáticas, tais como: inferências convidadas, tipo de conteúdo a que se refere, crenças e implicações conversacionais. Tendo em vista que a teoria admite que, em situações naturais de interação, as pessoas não são apenas pensadores lógicos, é totalmente aceitável que declarações com mesma forma sintática mas com conteúdos diferentes possam conduzir a conclusões totalmente diferentes. As inferências lógicas coexistem pacificamente com as outras formas de inferência no raciocínio cotidiano.

\section{Referências}

Byrne, R. M. J., Espino, O., \& Santamaria, C. (1999). Counterexamples and the suppression of inferences. Journal of Memory and Language, 40, 347-373.

Braine, M. D. S. (1978).On the relation between the natural logic of reasoning and the standard logic. Psychological Review, 85, 1-21.
Braine, M. D. S., \& O'Brien, D. P. (1998a). A theory of if: A lexical entry, reasoning program, and pragmatic principles. In M. D. S. Braine \& D. P. O’Brien (Orgs.), Mental logic (pp. 199-244). New Jersey: Erlbaum.

Braine, M. D. S., \& O'Brien, D. P. (1998b). The theory of mental-propositional logic: Description and illustration. In M. D. S. Braine \& D. P. O'Brien (Orgs.), Mental logic (pp. 79-90). New Jersey: Erlbaum.

Comrie, B. (1986). Conditionals: a typology. In E. C. Traugott (Org.), On conditionals (pp.77-99). Cambridge: Cambridge University Press.

Dias, M. G. B. B. (1996). O desenvolvimento do raciocínio dedutivo. In M. G. B. B. Dias \& A. G. Spinillo (Orgs.), Tópicos em psicologia cognitiva (pp.11-44). Recife: Editora Universitária da UFPE.

Dias, M. G. B. B., \& Harris, P. L. (1988). The effect of make-believe play on deductive reasoning. British Journal of Developmental Psychology, 6, $207-$ 221.

Geis, M. L., \& Zwicky, A. M. (1971). On invited inferences. Linguistic Inquiry, 2, 561-566

Girotto, V., Light, P., \& Colbourn, C. (1988). Pragmatic schemas and conditional reasoning in children. The Quarterly Journal of Experimental Psychology, 40A(3), 469-482.

Gouveia, E.L., Roazzi, A., O’Brien, D. P., Moutinho, A., \& Dias, M. G. B. B. (2002). Raciocínio dedutivo e lógica mental. Manuscrito submetido para publicação.

Guimarães, E. (1995). Os limites do sentido: um estudo histórico e enunciativo da linguagem. Campinas: Pontes.

Hirata, F. B. M. (1999). A hipotaxe adverbial condicional no português escrito contemporâneo do Brasil. Dissertação de Mestrado não-publicada. Universidade Estadual Paulista, Araraquara.

König, E. (1986). Conditionals, concessive conditionals and concessives: Areas of contrast, overlap and neutralization. In E. C. Traugott (Orgs.), On conditionals (pp. 229-246). Cambridge: Cambridge University Press.

Markovits, H. (1988). Conditional reasoning, representation, and empirical evidence on a concrete task. The Quarterly Journal of Experimental Psychology, 40A(3), 483-495.

O'Brien, D. P. (1987). The development of conditional reasoning: An iffy proposition. Advances in Child Development and Behavior, 22, 61-90.

O’Brien, D. P., Dias, M. G., Roazzi, A., \& Braine, M. D. S. (1998). Conditional reasoning: The logic of supposition and children's understanding of pretense. In M. D. S. Braine \& D. P. O’Brien (Orgs.), Mental logic (pp.245-272). New Jersey: Erlbaum.

O’Brien, D. P., \& Overton, W. F. (1980). Conditional reasoning following contradictory evidence: A developmental analysis. Journal of Experimental Child Psychology, 30, 44-61.

Rumain, B., Connell, J., \& Braine, M. D. S. (1983). Conversational comprehension processes are responsible for reasoning fallacies in children as well as adults: If is not the biconditional. Developmental Psychology, 19, 471-481.

Taplin, J. E. (1971). Reasoning with conditional sentences. Journal of Verbal Learning and Verbal Behavior, 10, 219-225.

Vadeboncoeur, I., \& Markovits, H. (1999). The effect of instructions and information retrieval on accepting the premises in a conditional reasoning task. Thinking and Reasoning, 5 (2), 97-113.

Wason, P. C. (1966). Reasoning. In B. M. Foss (Org.), New horizons in psychology (Vol 1, pp. 135-151). Harmondsworth: Penguin.

Wason, P. C., \& Johnson-Laird, P. N. (1972). Psychology of reasoning: Structure and content. Cambridge: Harvard University Press. 
2 Para mais detalhes sobre essa discussão, ver Gouveia, Roazzi, O’Brien, Moutinho e Dias (2002).

3 Tradução e negrito nossos.

4 Tradução e grifo nossos.

5 Ver Braine (1978) para discussão sobre as dificuldades em se adotar a tabela de verdade como verbete léxico para o se.

6 Para mais detalhes sobre o programa de raciocínio consultar Braine e O’Brien (1998b).

Edilaine Lins Gouveia é mestre em Psicologia Cognitiva pela Universidade Federal de Pernambuco. Antonio Roazzi, doutor em Psicologia pela Universidade de Oxford (Reino Unido), é professor do Departamento de Psicologia da Universidade Federal de Pernambuco.

Karina Moutinho, mestre em Psicologia Cognitiva pela Universidade Federal de Pernambuco, é professora substituta do Departamento de Psicologia da Universidade Federal de Pernambuco.

Maria da Graça Bompastor Borges Dias, doutora em Psicologia do Desenvolvimento pela Universidade de Oxford (Reino Unido), é professora do Departamento de Psicologia da Universidade Federal de Pernambuco. David Paul O'Brien, doutor em Psicologia pela Temple University (EUA), é professor do Department of Psychology do Weissman School of Arts and Sciences, Barush College, City University of New York, EUA. Endereço para correspondência: Pós-Graduação em Psicologia, Universidade Federal de Pernambuco, $\mathrm{CFCH}$, $8^{\circ}$ andar. Rua Acadêmico Hélio Ramos s/n, Cidade Universitária. 50.670-901, Recife. PE. Fone: (81)3271.8272, 3271.0599; Fax: (81)3271.1843. E-mail: [MGBBD] mdias@npd.ufpe.br. 